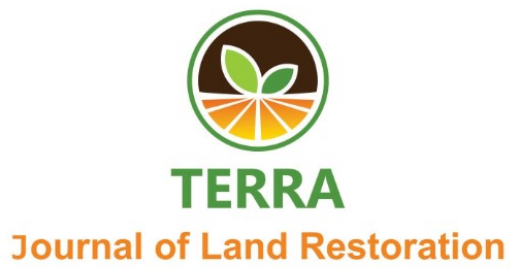

\title{
Effects of Arbuscular Mycorrhiza Fungi and Coffee Pulp Compost in Improving Soil Water Uptake by Chilli Around the Permanent Wilting Point Conditions
}

\author{
Ingri Dayana $^{1}$, Bandi Hermawan ${ }^{1}$,Yudhi H. Bertham ${ }^{1}$, Hasanudin ${ }^{1}$, Dwi W. Ganefianti ${ }^{2}$ \\ ${ }^{1}$ Soil Science Department, University of Bengkulu (Corresponding author) \\ ${ }^{2}$ Agronomy Department, University of Bengkulu \\ e-mail:bhermawan@unib.ac.id
}

\begin{abstract}
Soil water availability to the plants is a range of water content between the field capacity and the permanent wilting point (PWP) conditions. The PWP is defined as the lower limit of soil water content that the plant can extract water from the soil as indicated by the symptoms of wilting plants. This is because plant roots are unable to penetrate the soil micropores that contain the water. The study aims to analyze the effects of arbuscular mycorrhizal fungi (AMF) and compost in enhancing soil water absorption by the plant when the water content is close to the permanent wilting point. Four doses of $A M F\left(0,5,10\right.$ and 15 g.plant $\left.{ }^{-1}\right)$ and three doses of coffee pulp-made compost $(0,5$ and 10 ton.h $a^{-1}$ ) were arranged according to a randomized complete block design with three replicates. Results showed that the application of AMF significantly enabled the plant to improve water uptake when the soil water content was about at the permanent wilting point conditions. The AMF addition of $15 \mathrm{~g}$.plant ${ }^{-1}$ significantly prolonged the growing period of chili to wither and the plant showed the wilting symptoms at the soil water content of 5 to $7 \%$ lower than the no-AMF plants. Improved water uptake under water stress conditions was attributed to increases in the root colonization by $A M F$.
\end{abstract}

Keywords: Arbuscular Mycorrhiza Fungi; chilli; soil water; wilting point

\section{INTRODUCTION}

Soil water represents the water that occupies the inter- and within-aggregate pore spaces of the soil profile. It can be divided into two categories, i.e. shallow and groundwater, both of which have a great influence on our life (Nio et al., 2010). Shallow water plays important role in the plant growth including as a main component of the pant body, nutrient solvent in the soil pores to help nutrient absorption by the plant roots, distribution of nutrients throughout the plant body, and metabolism processes (Palupi \& Dedywiryanto, 2008). Therefore, the availability of shallow water in the pore spaces determines the growth and yields of plants particularly in the agricultural areas.

The plant-available water content (PAWC) is defined as a range of soil water content that lies between the field capacity where the maximum amount of water the soil can keep and at the permanent wilting point (PWP) in which the plant can no longer extract water from the soil (Hillel, 1980). The soil PAWC is a very important soil property that controls water and nutrient mobility to the plant roots. There are two approaches in understanding the soil PAWC, analyzing the macropores that hold the maximum water at the field capacity status and finding out the scientific efforts to extend fine roots that capable of inserting the water-holding micropores of less than $0.2 \mu \mathrm{m}$ in diameter (Hermawan, 2002). The later is very important in sustaining crop production under the water stress condition such as during the period of the dry season.

Arbuscular mycorrhizal fungi (AMF) have the formation of unique structures that help plants to capture water and nutrients such as phosphorus, sulfur, nitrogen, and micronutrients from the soil when the roots have been difficult to absorb water (Muzakkir, 2011). The fungi hyphae have a special ability in absorbing water from the very small pores in the soil because of their tiny size. The AMF also produces the antibiotic compounds to protect diseases and results in the growth regulators, such as auxin, cytokinin, and gibberellin, to promote the plant performance (Nurmasyitah et al., 2013; Simanjuntak, 2005). 
The present study aims to analyze the effects of arbuscular mycorrhizal fungi and compost on the ability of a plant to grow when the soil water content was close to the permanent wilting point status. It was assumed that the application of AMF and compost would enhance soil water capture by the plant when the soil was under drought conditions.

\section{MATERIAL AND METHOD}

The study was conducted from September 2019 to February 2020 in the greenhouse of Bengkulu University using a degraded soil taken from Muara Bangkahulu Municipality of Bengkulu City. The degraded study soil consisted of subsoil layers, dominated by sand and clay fractions, as well as low contents in organic matter and nutrient as shown in Table 1. The coffee compost, on the other hand, was characterized by high contents of organic carbon, nitrogen, and potassium, but low in phosphorous.

Table 1. Basic characteristics of soil and coffee pulp compost that were used in the current study

\begin{tabular}{|l|c|c}
\hline \multicolumn{1}{|c}{ Variables } & Soil & Compost \\
\hline Sand (\%) & 39.32 & \\
\hline Silt (\%) & 12.14 & \\
\hline Clay (\%) & 48.55 & \\
\hline C-organic (\%) & 0.4 & 15.4 \\
\hline N (\%) & 0.07 & 1.23 \\
\hline P (ppm) & 3.65 & 0.98 \\
\hline K (me/100 mg) & 0.09 & 1.02 \\
\hline pH & 4.5 & 6.75 \\
\hline
\end{tabular}

Four doses of AMF $\left(0,5,10\right.$ and 15 g.plant $\left.{ }^{-1}\right)$ and three doses of coffee-made compost $(0,5$ and 10 ton.ha $\mathrm{a}^{-1}$ ) were arranged according to a randomized complete block design with three replicates. Each experimental unit was set for two plants, therefore, there were 72 plant media used in the study. The airdry soil was sieved using a $5-\mathrm{mm}$ sieve, $10 \mathrm{~kg}$ of $0-5$ aggregates were put into a polybag (soil water content was $0.15 \mathrm{~g} \cdot \mathrm{g}^{-1}$, therefore, the soil weight was equal to $8.69 \mathrm{~kg}$ ). Inoculation of AMF to the soil media was conducted according to the experimental treatments by following the Technical Guidance published by Bertham \& Inoriah (2009). Air-dry compost was also added and mixed in the soil media according to the treatments. The media was then planted with the threeweek young plant of chili and subject to plant maintenance including watering and plant protection.

At the end of the experimental period, the plants were left unirrigated until showing the wilting symptoms, soil gravimetric water content at the permanent wilting point was then measured in-situ using the Dielectrometer (Hermawan et al., 2017). This variable indicated the ability of plants with treatments to absorb water when the soil water content at the PWP status. Soil bulk density was calculated by measuring the height of soil media in the polybag, then multiplied with the gravimetric water content to get the volumetric water content of the soil. The number of root colonization by AMF was analyzed using the Stanning Method and observed visually under a microscope.

\section{RESULT AND DISCUSSION}

Soil water content when the plant showed the wilting symptoms

Analyses of variance showed that the AMF application significantly affected soil water content at the time of the plant showed the wilting symptoms, as well as the number of root colonization. The 5\% test of least significant difference showed that the addition of 15 g.plant ${ }^{-1}$ AMF resulted in the significantly lower soil water content at the time of the plant wilting symptoms compared to no AMF application (Table 2 ). At the end of the experiment, no water was added to the planting media and chili began to be wilt when the no-AMF soil water content was at $0.37 \mathrm{~g}^{-g^{-1}}$ or $0.44 \mathrm{~cm}^{3} . \mathrm{cm}^{-3}$. However, the plant with the AMF application of 15 g.plant ${ }^{-1}$ would show the wilting symptoms at $0.32 \mathrm{~g} . \mathrm{g}^{-1}$ or $0.37 \mathrm{~cm}^{3} \cdot \mathrm{cm}^{-3}$. The application of AMF inoculant with lower doses showed less improvement and had no-significant differences with control.

Table 2. Averages in soil water content when the plant showed wilting symptoms. Each number was the average from nine data

\begin{tabular}{|c|c|c|}
\hline $\begin{array}{c}\text { AMF Doses } \\
\left(\text { g.plant }^{-1}\right)\end{array}$ & $\begin{array}{c}\text { Gravimetric } \\
\text { Water }\left(\mathrm{g}^{-1} \mathrm{~g}^{-1}\right)\end{array}$ & $\begin{array}{c}\text { Volumetric } \\
\text { Water } \\
\left(\mathrm{cm}^{3} \cdot \mathrm{cm}^{-3}\right)\end{array}$ \\
\hline 0 & $0.37 \mathrm{a}$ & $0.44 \mathrm{a}$ \\
\hline 5 & $0.36 \mathrm{a}$ & $0.42 \mathrm{a}$ \\
\hline 10 & $0.35 \mathrm{a}$ & $0.40 \mathrm{ab}$ \\
\hline 15 & $0.32 \mathrm{~b}$ & $0.37 \mathrm{~b}$ \\
\hline $\begin{array}{l}\text { The numbers in each column followed with the } \\
\text { same character were not significantly different } \\
\text { (P>0.05). }\end{array}$ \\
\hline
\end{tabular}

The application of up to 10 ton.ha $^{-1}$ coffeemade compost did not affect significantly the soil water content at the time of the wilting plants. Although compost has been well-known for the improvement of soil water availability to the plant, it 
seemed that the improvement occurred at the field capacity condition not in the permanent wilting point. A study by Głąb et al. (2018), for example, found that addition of the compost improved significantly soil water content and the number of pores less than $50 \mu \mathrm{m}$ in diameter, it could not help the plant roots to capture water at the pores smaller than $0.2 \mu \mathrm{m}$. Therefore, there was no significant contribution of coffee pulp compost in the enhancement of soil water capture at the permanent wilting point when AMF was added to the soil as shown in Table 2.

\section{Root colonization by $A M F$}

The number of root colonization in chili increased pronouncedly with the application of AMF to the soil media (Figure 1). The effects of AMF on the root colonization level were observed and expressed as the number of fungal symbionts as visualized in Figure 2. The root-fungal symbiont as shown in Figure 2 increased with AMF application compared to the non-mycorrhizal roots. The relations between AMF doses and the root colonization were similar to findings reported earlier by Medina et al. (2003). However, the degree of colonization improvements with AMF doses was strongly influenced by the presence of the coffee pulp compost. The AMF used the compost as an energy source for living, therefore, the root colonization response to AMF was much higher with the application of compost.

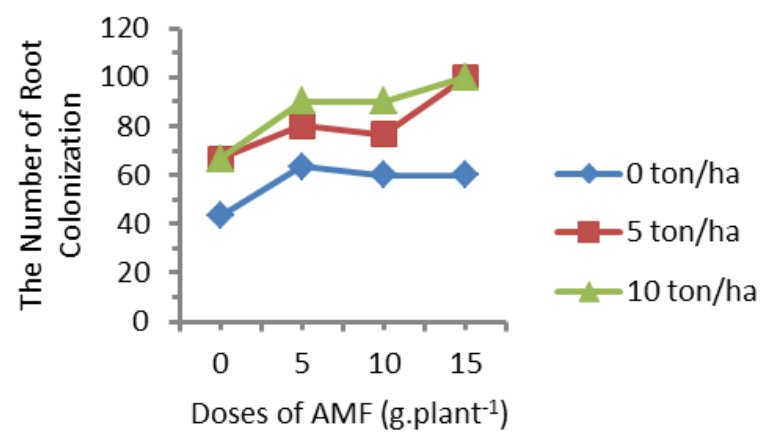

Figure 1. Effects of AMF doses on the number of root colonization with 0,5 and 10 ton.ha ${ }^{-1}$ addition of the coffee pulp compost

The findings suggested that the addition of 15 g.plant ${ }^{-1}$ AMF enabled chili to uptake about $15 \%$ more water held by micropores that the no-AMF plants were no longer able to absorb it. They approved that AMF was very important in enhancing the water and nutrient absorption by the plant (Setiadi, 1995). The role of AMF in increasing the plant capture ability of water content under water stress conditions was attributed to the number of root -fungi symbiont at the AMF-added plants. A result

TERRA,3(1), 23-26 (2020) of regression analysis in Figure 3 suggested that about $92 \%$ of the variations in soil water content at the plant -wilting symptoms were explained by the variations in the number of root colonization by AMF. The equation in Figure 3 indicated that every addition of ten root colonization could lower the minimum level of soil water content by $1.5 \%$ in which the plant could no longer absorb water from the soil matrix.
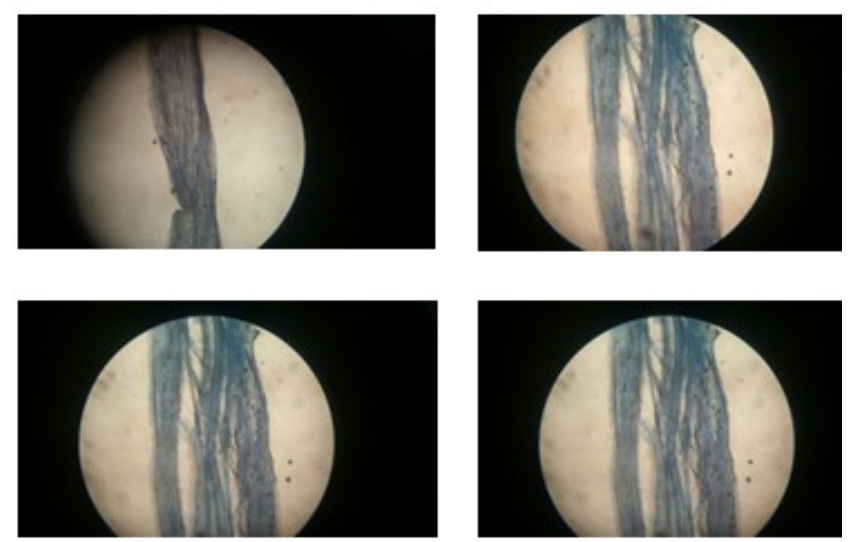

Figure 2. Visualization of the number of root colonization with different doses of AMF. From left: 0, 5, 10 and 15 g.plant ${ }^{-1}$

Results of the current study provided a new promoting approach in maintaining land productivity under water stress period such as during a long term period of the dry season as occurred in 2019. This proposed approach agreed with other studies that the AMF colonization had a good relation with drought stress mitigation (Salloum et al., 2018), therefore, improved nutrient uptake and chili's growth (Halis et al., 2008). Effects of soil water stress on plant production have also been reported by Yang et al. (2018) in which the significant reduction in the chili pepper yield occurred when the 25 and 50\% deficit irrigation was applied. It was necessary, therefore, to conduct further studies regarding detail techniques in applying AMF to allow other plant species to capture more water under soil water stress conditions.

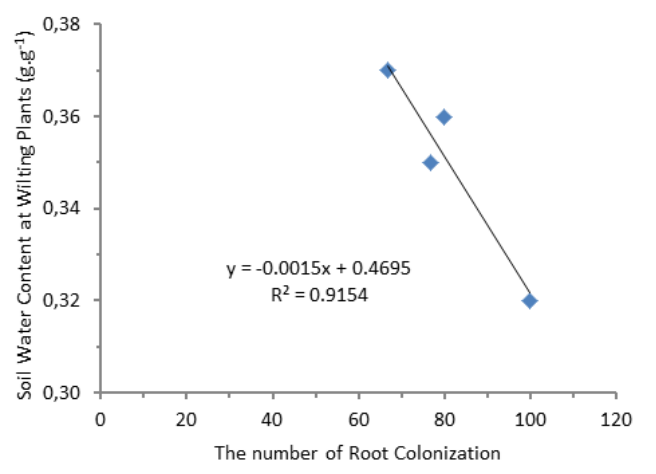

Figure 3. A relation between the number of root colonization with soil water content at the time of the plants showed the wilting symptoms 


\section{CONCLUSION}

The application of up to 15 g.plant $^{-1}$ AMF significantly enabled the plant to absorb more water when the soil water content was about at the permanent wilting point conditions. The AMF addition of 15 g.plant ${ }^{-1}$ significantly prolonged the growing period of chili to wither and the plant showed the wilting symptoms at the soil water content of 5 to $7 \%$ lower than the noAMF plants. Improved water uptake under water stress conditions was attributed to increases in the root colonization by AMF.

\section{Declaration of competing interests}

The authors declare that they have no known competing for financial interests or personal relationships that could have appeared to influence the work reported in this paper.

\section{Acknowledgment}

This research was partly funded by the Directorate of Research and Community Service, Ministry of Research, Technology and Higher Education Republic of Indonesia, Contract No: 165/SP2H/LT/ $\mathrm{DRPM} / 2019$.

\section{References}

Bertham, Y. H. \& Inoriah, E.S. (2009). Effects of double inoculation of abuscular mycorrhizal fungi and indigenous rhizobium on three genotypes of soybean in Ultisols. Akta Agrosia, 12 (2), 155166.

Głąb, T., Żabiński, A., Sadowska, U., Gondek, K., Kopeć, M., Mierzwa-Hersztek, M. \& Tabor, S. (2018). Geoderma, 315, 27-35. DOI: https://10.1016/ j.geoderma.2017.11.034.

Halis, P. Murni \& Fitria, A.B. (2008). Effects of types and doses of Arbuscular Mycorrhizal Fungi on the growth of chili (Capsicum annuum L.) in Ultisols. Biospecies, 1(2), 59-62.

Hermawan, B. 2002. Teaching Book of Soil Physics. BPFP, Bengkulu.

Hermawan, B., Suparjo, E., Hindarto, K.S., Silalahi, R. \& Barchia, F. (2017). A quick dielectric method to determine in-situ soil water content for precision water use under sustainable agricultural practices. International Journal on Advanced Science, Engineering Information Technology. 7(3), 3-8. DOI: https://10.18517/ ijaseit.7.3.1667.

Hillel, D. (1980). Introduction to Soil Physics. Academic Press, Inc., London, Toronto, 364 pp.

Medina, M.J.H., Piché, Y., Gagnon, H. \& Ocampo, J.A. (2003). Root colonization by arbuscular mycorrhizal fungi is affected by the salicylic acid content of the plant. Plant Science, 164(6), 993-998. DOI: https://10.1016/S0168-9452(03) 00083-9.

Muzakkir. (2011). Relations between abuscular mycorrhizal fungi and soil chemical properties in the critical land of Tanjung Alai West Sumatera. [Hubungan Antara Cendawan Mikoriza Arbuskular Indigenous \& Sifat Kimia Tanah di Lahan Kritis Tanjung Alai Sumatera Barat.] Jurnal Solum, 8(2), 53-57.

Nurmasyitah, Syafruddin \& Sayuthi, M. (2013). Pengaruh Jenis Tanah \& Dosis Fungi Mikoriza Arbuskular Pada Tanaman Kedelai Terhadap Sifat Kimia Tanah. Jurnal Agrista. 17(3), 103110.

Palupi, E.R. \& Dedywiryanto, Y. (2008). Analyses of drought-tolerance characteristics for four genotypes of oil palm nursery (Elaeis guineensis Jacq.) [Kajian karakter toleransi cekaman kekeringan pada empat genotipe bibit kelapa sawit (Elaeis guineensis Jacq.)]. J. Agron, 36(1), 24-32.

Salloum, M.S., Menduni, M.F. \& Luna, C.M. (2018). The differential capacity of arbuscular mycorrhizal fungal colonization under well-watered conditions and its relationship with drought stress mitigation in unimproved vs. improved soybean genotypes. Botany, 96(2), 135-144.

Simanjuntak, D. (2005). Roles of trichoderma, mycorrhiza dan phosphor for the growth of soybean on the sulfate acid soils (Humitropets). $J$. Agro. 7(1), 51-55.

Yang, H., H. Liu, Zheng, J. \& Huang, Q. 2018. Effects of regulated deficit irrigation on yield and water productivity of chili pepper (Capsicum annuиm L.) in the arid environment of Northwest China. Irrigation Science, 36(1), 61-74. DOI: $\quad$ https://doi.org/10.1007/s00271-0170566-4. 